\title{
Family sources of educational gender inequality in rural china: A critical assessment
}

\author{
Emily Hannum ${ }^{a},{ }^{*}$, Peggy Kong ${ }^{b}$, and Yuping Zhang ${ }^{c}$ \\ aUniversity of Pennsylvania, Department of Sociology and Population Studies Center, 3718 Locust \\ Walk, Philadelphia, PA 19104-6299, United States \\ bUniversity of Wisconsin, Madison, WI, United States \\ 'Lehigh University, Bethlehem, PA, United States
}

\section{Abstract}

In this paper, we investigate the gender gap in education in rural northwest China. We first discuss parental perceptions of abilities and appropriate roles for girls and boys; parental concerns about oldage support; and parental perceptions of different labor market outcomes for girls' and boys' education. We then investigate gender disparities in investments in children, children's performance at school, and children's subsequent attainment. We analyze a survey of 9-12-year-old children and their families conducted in rural Gansu Province in the year 2000, along with follow-up information about subsequent educational attainment collected 7 years later. We complement our main analysis with two illustrative case studies of rural families drawn from 11 months of fieldwork conducted in rural Gansu between 2003 and 2005 by the second author.

In 2000, most mothers expressed egalitarian views about girls' and boys' rights and abilities, in the abstract. However, the vast majority of mothers still expected to rely on sons for old-age support, and nearly one in five mothers interviewed agreed with the traditional saying, "Sending girls to school is useless since they will get married and leave home." Compared to boys, girls faced somewhat lower (though still very high) maternal educational expectations and a greater likelihood of being called on for household chores than boys. However, there was little evidence of a gender gap in economic investments in education. Girls rivaled or outperformed boys in academic performance and engagement. Seven years later, boys had attained just about a third of a year more schooling than girls-a quite modest advantage that could not be fully explained by early parental attitudes and investments, or student performance or engagement. Fieldwork confirmed that parents of sons and daughters tended to have high aspirations for their children. Parents sometimes viewed boys as having greater aptitude, but tended to view girls as having more dedication-an attribute parents perceived as being critical for educational success. Findings suggest that at least in Gansu, rural parental educational attitudes and practices toward boys and girls are more complicated and less uniformly negative for girls than commonly portrayed.

\section{Introduction}

In poor rural settings in China, girls' access to education has long been a focus of scholarly and policy attention. However, the degree to which girls in such settings remain disadvantaged relative to their male counterparts is poorly established. Since the 1980s, researchers have often cited traditional attitudes about girls' and women's abilities and roles or different expected

\footnotetext{
(c) 2009 Elsevier Ltd. All rights reserved

*Corresponding author. E-mail address: hannumem@soc.upenn.edu (E. Hannum)..
} 
returns to the family for educating sons and daughters as reasons that girls' education might be disadvantaged (Honig and Hershatter, 1988; Wolf, 1985). Families could expect different returns because they perceive a gender gap in the earnings outcomes of schooling or because they anticipate old-age support from sons more than from daughters (Jacka, 1997; Andors, 1990). These attitudes or expectations may translate into differences in investments in children, based on their gender; differences in treatment may translate into differences in children's own educational performance. Eventually, some combination of these factors is thought to lead to differences in educational attainment that favor boys.

However, no empirical studies have directly investigated links between parental attitudes and behaviors, on the one hand, and gender gaps in children's education, on the other. Moreover, recent changes in China suggest that the context of educational decisions is changing quickly. Educational access is expanding, and the prospect of migration is challenging traditional assumptions about family relationships and generational dependence, and transforming prospects for non-farm work for women and men.

This paper offers a case study of family sources of educational gender inequality in rural Gansu, in China's northwest. We investigate mothers' gender-related attitudes and expectations, family investments in children, and children's performance and educational engagement. We then investigate the degree to which these factors play a role in children's subsequent attainment, and the gender gap therein. We employ a survey of 9-12-year-old children and their families conducted in rural Gansu Province in the year 2000, along with follow-up information about subsequent educational attainment collected 7 years later. We complement our main analysis with two illustrative case studies of rural families drawn from 11 months of fieldwork conducted in rural Gansu between 2003 and 2005 by the second author.

\section{Educational gender inequality in China}

The context of this study is one of long-term declines in gender inequality in China (e.g., Hannum, 2005; Zhou et al., 1998; Bauer et al., 1992). By the 1990s, gender disparities in China were concentrated in poor rural areas, and among poor households, where children compete with more siblings for educational resources and the costs of education are a burden on families (Connelly and Zheng, 2003). Girls who live in suburban villages and villages where there are more non-farm opportunities than farm opportunities stay in school longer (Michelson and Parish, 2000). Fewer differences in enrollment or in other dimensions of basic education are found in urban areas, where schooling is better subsidized, where families are less resource constrained, on average, and where children compete with fewer (or no) siblings for resources. One study of only children in urban China found no gender differences in parental spending on children's education, student achievement in math, and educational aspirations of the student (Tsui and Rich, 2002). ${ }^{1}$ In rural areas, where the majority of the population resides and where the gender gap remains potentially problematic, little empirical research has emerged beyond studies documenting gaps in enrollment or attainment.

\section{Framework}

Three related categories of explanation can be used to theorize about family factors that might create enrollment and attainment gaps in poor rural settings in China. First, parents (or, in our operationalization, mothers), carry overtly discriminatory attitudes about girls' and boys' essential academic and working abilities and rights; second, parents make choices in response to perceptions of treatment of men and women in the broader society; and third, parents make

\footnotetext{
${ }^{1}$ The authors attribute this finding in part to the one-child policy, which eliminates family incentives to discriminate against girls, once they are in the family.
} 
choices in direct response to economic incentives to the family (not just to the child). Here, we briefly outline each of these categories in relation to theories of gender stratification.

The first explanation is cultural: the notion that attitudes that overtly devalue girls persist, forming a context within which low levels of investment in and aspirations for daughters are normative. An article by Ridgeway and Correll (2004) neatly summarizes the role of cultural rules in generating systems of gender stratification:

A social structure, argued Sewell (1992), can be understood as jointly constituted by the cultural rules or schemas by which it is enacted and the distributions of resources that result. Viewed this way, gender beliefs, as the cultural rules or schemas for enacting gender, are one of the twin pillars (along with resources) on which the gender system rests (Ridgeway and Correll, 2000). It is only through the development of such defining cultural beliefs that a system of difference like gender...becomes constructed as a distinct organizing principle of social relations (Ridgeway, 2000). (p. 511)

Applying this theory to the case of education, investment and socialization decisions made by parents are colored by cultural perspectives about essential abilities, rights and roles of men and women; these cultural perspectives become reified in the different investments, and ultimately educational opportunities, made available to boys and girls. This perspective has been used to analyze and explain gender disparities in educational attainment in the past in rural communities in the United States. For example, studies among rural Appalachian families in the 1970s and 1980s have suggested a high degree of retention of traditional gender role orientations, such that status attainment was perceived as more important for sons than for daughters (Hennon and Photiadis, 1979; Wilson et al., 1993).

In rural China, ethnographic studies and educational research in the 1980s suggested that families retained beliefs that girls were less worthy of education or less capable than boys (Lo, 1984;Rosen, 1984;Honig and Hershatter, 1988;Wolf, 1985). One study directly tied son preference among mothers to traditional culture: analyzing a 1994 survey of women in a rural county in southwest China who bore children between 1991 and 1994, Li and Lavely (2003) showed that women in households that practice traditional ancestor worship express a stronger preference for sons. As a result of traditional beliefs, scholars have argued, restrictions were placed on the educational and workplace opportunities available to women (Wolf, 1985). This explanation could be regarded as a cultural or patriarchal explanation, working through parents' aspirations for, treatment of, and socialization of children. However, few studies in the ensuing years have investigated the prevalence or impact on schooling decisions of directly discriminatory attitudes.

A second broad category of explanations for gender disparities in investments in children focuses not on the values and attitudes of parents about girls themselves, but rather in decisions taken under perceptions that the labor market, and adult life more broadly, are likely to treat girls and boys differently. For example, in the past, research in rural Appalachian settings in the US has suggested that the gender-based division of labor among adults shapes parental socialization of and aspirations for children from an early age, with the consequence of poorer educational and occupational trajectories for girls (Hennon and Photiadis, 1979; Wilson et al., 1993).

Current research in some developing societies characterized by extreme labor market segmentation by sex must account for the fact that returns to education for boys are seen in terms of increased labor market opportunities, but these increases are almost negligible for girls (Mahmud and Amin, 2006). For example, speaking about rural Bangladesh, Mahmud and Amin (2006) argue that the marriage market, more than the labor market, must be seen as the means of economic returns to, and the prime motivation for, girls' education. Consistent with 
this line of thinking, Jennifer Rothchild's (2006) fieldwork among families and teachers in a rural Nepalese village found that parents spoke of girls' education "in terms of their presumed current and future roles as daughters, wives, mothers, and daughters-in-law, rather than as a source of individual opportunity and empowerment" (p. 106).

In rural China, adult roles are not so rigidly differentiated by sex as in the rural South Asian examples just given. However, in the 1980s and 1990s, some scholars argued that reforms in China caused a so-called feminization of agriculture, in which rural women are concentrated in agricultural occupations, while men are more likely to have access to higher-paying rural industrial jobs where educational credentials carried greater weight (Summerfield, 1994; Wolf, 1985). This phenomenon would serve as a disincentive to educate girls beyond a certain level. Similarly, in explaining girls' enrollment disadvantage, Michelson and Parish (2000) speculate that because women are perceived as less able to contribute to family cash income, due to their concentration in farm work, families may feel it unnecessary to educate girls and women at the same level as boys. Yet, whether rural girls indeed face poorer off-farm employment prospects than their male counterparts is debatable, given the dramatic rise of migration to urban areas, by young women and men, for informal work in recent years.

These first two categories of explanation focus on how parents make choices about girls and boys, for the children's own sake: aspirations for and investments in boys and girls are colored by parents' differing views about boys and girls themselves, or about their prospects in the job market. However, by necessity, many rural parents in China are making educational decisions based not only on their perceptions about what is appropriate for the child, but also on what they think is best for the family's economic future. This situation is common in rural Asia (see Mahmud and Amin, 2006, for rural Bangladesh, and Rothchild, 2006, for rural Nepal), and, indeed, most studies of enrollment or attainment disparities in developing countries adopt a framework in which households make decisions about schooling primarily or exclusively based on expectations of future returns to the household, rather than to the individual child (for articulations of this view, see Papanek, 1985 or Mahmud and Amin, 2006).

In most rural areas of China, sons are the primary source of oldage support. Girls have typically married out of households, while boys remain with families of origin (Hooper, 1991; Honig and Hershatter, 1988). ${ }^{2}$ To the extent that the tradition of co-residence with sons holds, parents face strong incentives to invest in sons as long-term insurance (Greenhalgh, 1994; Wolf, 1985). Research in a rural county in Yunnan Province indicates that expectations of support from sons are more pronounced among mothers in poorer, more remote rural areas $(\mathrm{Li}$ and Lavely, 2003). The expected lack of access to the earnings of adult daughters provides a clear financial incentive, especially to poorer families, to forego the direct and opportunity costs associated with educating daughters, and to allow them to contribute to the household economy until departure to married life (Lin, 1993). Thus, family structures and intergenerational coresidence patterns, themselves colored by cultural norms about gender roles, can create rational incentives that privilege investments in sons more than daughters (Jacka, 1997; Andors, $1990) \cdot 3$

Drawing a set of specific hypotheses from the arguments outlined above, this study begins to fill in the empirical gap with an investigation of gender attitudes and practices in the household and their implications for rural boys' and girls' educational differences. Fig. 1 summarizes a framework for understanding gender inequalities in rural China, grounded in previous studies.

\footnotetext{
${ }^{2}$ This co-residence pattern is found in other parts of Asia, where it has also been linked to schooling decisions. For example, for Nepal, see Rothchild (2006).

${ }^{3}$ However, see Jin et al.'s (2002) research suggesting that parents invest more resources in sons' education than daughters', even when they expect daughters to remain in the natal home and bring in a husband.
} 
Box 1 represents parental attitudes about gender, and specifically three hypotheses:

H1. Families think that daughters are less capable, or less worthy of investment.

H2. Families expect that sons' returns to education will be better than daughters' in the labor market.

H3. Families expect future support from sons more than from daughters.

These statements represent traditional attitudes about girls' abilities and rights (in the case of Hypothesis 1) and the expected returns to the child and family economic arguments (in the cases of Hypotheses 2 and 3).

Box 2 represents the investment decisions that families might make differently for boys and girls, depending on the attitudes listed in Box 1. Investments include economic resources, such as education-related expenditures on children, and the provision of a learning environment, for example through providing books or helping with homework. The literature also suggests that gender differences in investments might occur through competition for time: choices about assignment of chores to girls or boys. For example, some scholars have argued that rural women's workload increased as production shifted from the commune back to the individual household (Jacka, 1997). To handle this workload, scholars have suggested that women may shift domestic work to their daughters (Wang, 1989; Hooper, 1991). Finally, an important psychological investment in children lies in parental (here, maternal) aspirations for them. We test these differences with Hypothesis 4:

H4. Parents invest less in the education of girls than boys.

Box 3 shows the next step, namely investigating gender differences in children's educational performance. Our performance indicators encompass both academic achievement, measured by grades, and engagement with the schooling process, such as children's willingness to spend time doing homework, children's feelings of belonging at school, their educational aspirations, and their academic confidence.

H5. Girls have poorer educational performance than boys do.

It is possible that children's performance may feed back into later parental attitudes and investments, but we do not explore this possibility in the current paper. Instead, we investigate the link between early attitudes, investments, and performance and later attainment. Box 4 represents the final outcome: gender differences in attainment. We consider three issues: whether there are gender differences in subsequent attainment; whether the variables included in Boxes 1-3 significantly predict later attainment; and if these variables help to explain the gender gap in attainment. With this approach, we test a final hypothesis:

H6. As a result of Hypotheses 1-5, girls have poorer attainment outcomes than boys do.

\section{Data and measures}

\subsection{Study site}

As we noted in the preceding section, gender disparities in basic education in China have narrowed dramatically in recent years, and remain a concern primarily on poorer rural settings. The study site for this paper, Gansu, is one of China's impoverished interior provinces (see Plate 1Map 1). Located in China's center to northwest, Gansu stretches across parts of the Gobi desert, mountainous and hilly areas, and vast grasslands. Most of Gansu's geography is mountainous or highland plateau, with an elevation of more than $1000 \mathrm{~m}$ (UNESCAP, 2003). 
In the year 2000, Gansu Province had a population of 25.62 million, $76 \%$ of whom resided in rural areas (UNESCAP, 2003). Rural residents in Gansu are predominantly employed in subsistence farming or animal husbandry, earning an average annual per capita income that was only $63 \%$ of the national average in the year 2000 (Gansu Socio-economic Development Report, 2001). Gansu has one of the highest incidences of rural poverty among provinces in China, and Gansu's population lags significantly by educational indicators (World Bank, 2000). According to statistics compiled by UNESCAP (2003), Gansu has the second-highest illiteracy rate in China. Moreover, in the year 2000, analyses of census data show that Gansu was one of three provinces in China where the difference in rural boys' and girls' percent attending middle school was $10 \%$ or more (Connelly and Zheng, 2007, Table 4).

\subsection{Survey data}

Our main analysis draws on survey data from the Gansu Survey of Children and Families (GSCF), a multi-level, longitudinal survey designed to increase understanding of rural children's schooling and welfare in the context of poverty. The project followed 2000 children ages 9-12 in the years 2000, 2004, and 2007. Map 1 shows the distribution of the sample across counties in Gansu. The sample was drawn using a multi-stage, clustered design with random selection procedures employed at each stage (county, ${ }^{4}$ township, village, and child). At the final stage, children were sampled from birth records for the full cohort of 9-12-year-old children in 100 selected villages. Of these children, $98.9 \%$ were currently enrolled in school in $2000 .^{5}$ The sample included only rural villages, and did not include cities or townships. In China, the urban-rural designation is official, clearly defined, and consequential for access to services, and so drawing a sample of rural villages was a clear-cut task. In terms of income, our sample is broadly representative of rural Gansu: the per capita incomes of $46 \%$ of the households in our sample (or 920 households) were above the provincial average. The remaining 54\% of households (or 1080 households) had per capita incomes that were below the provincial average (Gansu Statistics Bureau, N.D.).

This paper refers to data collected in 2000 from the mother, household head, child and homeroom teacher questionnaires, and data collected in 2007 from the household questionnaires. A total of 2000 children were interviewed in the year 2000, and 92\% (1844 children) were found at re-interview in 2007. All variables except the outcome of child's attained years of schooling in 2007 were measured in the year 2000. For descriptive tables, all cases with valid data on each individual variable are included. For multivariate analysis of attainment, we restrict the sample to those who were enrolled in 2000 (1822), because we use early achievement in some specifications. We then dropped 16 cases in total due to very small numbers of missing cases on some independent variables, leaving us with an analytic sample of $1806 .{ }^{6}$ For other variables with missing data, we created a missing category so that we would not exclude these observations from analysis and so that we could test whether those with missing observations were significantly different from those with observed data. For continuous variables, a "0" value along with a missing indicator are added. We employ variables tapping into each dimension of the framework in Fig. 1. These variables are described below.

\footnotetext{
${ }^{4} \mathrm{~A}$ handful of minority counties were closed to internationals at the time of the initial data collection, and so were excluded from the sampling frame. The GSCF does not have sufficient numbers of minority children to allow for analysis of ethnic differences in educational outcomes.

${ }^{5}$ This number is similar to the enrollment rate for school-aged children in Gansu reported by UNESCAP for the year 2000, at $98.83 \%$. However, the UNESCAP number is almost certainly an enrollment ratio (enrollments from one source, base population from another), rather than a rate based on a survey of children. Whether it is a gross or net enrollment ratio, and the age range to which it refers, are not specified (UNESCAP, 2003). Nationally, gross enrollment ratios at the primary level have long been above 100\%, reflecting a high level of out-of-age-range enrollment. For example, for the 2002-2003 academic year, the national gross enrollment ratio was 115 (UNESCO Institute for Statistics, 2005).

${ }^{6}$ Three cases were dropped due to missing data on the educating girls is useless variable; one case was dropped for missing data on the good student question; five cases were dropped due to missing data on child aspirations, and seven cases were dropped due to missing data on the parents should rely on sons for old-age support.
} 


\section{Parental attitudes}

\subsection{Girls' capabilities and worthiness}

To address our research question regarding traditional parental attitudes, we consider beliefs held by parents regarding capabilities of girls and boys. Mothers were asked whether they disagreed, had no opinion or agreed with the following statements: If they work hard, girls can do as well as boys in school; Girls should enjoy the same opportunities for education as boys; Given equal opportunities, women can achieve the same things as men; and Parents should encourage girls to think as independently as boys.

\subsection{Expected returns to girls' and boys' schooling}

Next, we examine if mothers perceived different returns to schooling for their girl children and boy children. First, we asked mothers separate questions about the level of influence of additional education on sons' future income and daughters' future income. The questions included, Compared to primary school, what is the influence of junior high school on sons' (or daughter's) income? Compared to junior high school, what is the influence of senior high school on sons' (or daughter's) income? We then include an explicit question designed to tap into gender discrimination in the labor market: Does education influence sons' income more than daughters'?

\subsection{Expectations of future support}

Finally, we consider economic incentives related to future support. Mothers were presented with two statements. The first statement captured traditional beliefs about co-residence, and the second statement linked co-residence to attitudes about the value of educating girls. We asked mothers if they disagreed, had no opinion or agreed with the following statements: Parents should rely on sons for care-giving in their old age and Sending girls to school is useless since they will get married and leave home.

We then asked mothers a more concrete set of questions about their own expectations of future support. We asked whether they expected to receive a lot, some or very little economic support from children: How much financial help do you think you will get from your children? We then asked, From which child do you expect to receive the most financial support from in the future?. Mothers could respond that they expected most support from a son or a daughter.

\section{Parents' investments}

To capture the provision of resources in the home, we include information about economic resources, the learning environment, competition for child's time and parental aspirations. In order to capture economic expenditures, we sum responses to questions administered to household heads about educational expenditures for the most recent semester for the target child, including tuition and textbooks, room and board, transportation, supplemental lessons, and other fees.

To capture the provision of a learning environment to the child, we employ two variables reported by the mother: How many books does the child have? and How frequently do parents spend time helping the child on homework? (never, sometimes, often). To capture time constraints involving domestic chores, we asked mothers, Do you (or your spouse) ordinarily require your child to do the following activities? ...common household chores, like washing dishes, helping in the kitchen, etc.? (never, sometimes, often). Finally, to capture parents' psychological investments in children, we asked mothers, What is the highest level of education you expect that your child can achieve? (primary, junior high school, senior high school, college or higher). 


\subsection{Children's educational performance}

To capture children's educational performance, we include measures of academic achievement, industriousness, alienation, academic confidence and educational aspirations. Academic achievement is measured as previous semester math and Chinese scores, scored out of 100 . To tap industriousness, the target child was asked about the amount of time spent on homework on a daily basis: Last semester, or when you were in school, how much time did you spend doing homework every day? Response categories were less than $1 \mathrm{~h}, 1-2 \mathrm{~h}$, or $3 \mathrm{~h}$ or more. To understand the child's feelings of alienation from school, we asked children to strongly disagree, disagree somewhat, agree somewhat, or strongly agree with the statement, A lot of the time, I do not want to go to school. To tap into children's confidence in school, we asked them asked about their self-concept as a student: Are you a good student? Response categories included no, somewhat, and yes. Finally, to tap into children's hopes for their educational future, we asked about aspirations: What is the highest level of education you want to achieve? (primary, junior high school, senior high school, college or higher).

\subsection{Children's subsequent educational attainment}

To assess whether girls and boys eventually attained different amounts of schooling, we use the total years of schooling attained by the child, as assessed in the 2007 follow-up survey.

\section{Control variables}

Finally, we use an additional set of variables, all measured in 2000, in order to avoid confounding by other factors correlated with attitudes, investments, and outcomes. We select a standard set of family socio-economic and demographic variables thought to affect schooling outcomes. We control for wealth using wealth quintiles to allow for possible non-linear effects of extreme poverty. We control for parental education with two variables: total "human capital" in the household, measured as parents' total years of schooling. We also control for child's age at the time of the survey.

Additionally, we control for numbers of siblings in the household. In research on the demography of schooling, siblings are thought to compete for household resources, and thus increasing the number of siblings tends to reduce educational attainments. In societies characterized by son preference, girls and boys may differently dilute resources. In societies characterized by extended families, older children may not dilute resources, but actually contribute to them, while younger children may especially dilute resources by requiring minding. For these reasons, wemeasure sibship as numbers of older and younger sisters and brothers.

\section{Case study data}

We complement our main analysis with two illustrative case studies of individual families compiled by the second author. Case study data were collected as part of an 11-month field study of parental involvement in children's schooling in a rural community in Gansu that took place during the years 2003 and 2005. The selected community was in a county that was part of the GSCF survey. The study included participant observation in classrooms and in-depth interviews with 35 sixth graders and their parents, five teachers, one principal, one district education leader, and one county education bureau leader. Family interviews were conducted over the course of two to three visits, with the duration of each visit averaging about $3 \mathrm{~h}$. Interviews and observations explored family relations, educational attitudes and expectations; gender attitudes; and school-family relationships. All interviews were audio-taped, transcribed, and coded by the second author. A loosely structured, emergent and inductive approach was used to analyze the data (Emerson et al., 1995; Miles and Huberman, 1994; Strauss and Corbin, 1998). Analytic themes developed during analysis within each family and then across families 
using open inductive coding. Here, we use the educational deliberations of two families that contained both school-aged girls and boys to illustrate views about gender and education that emerged consistently in the larger field study.

\subsection{Analysis of survey data}

8.1.1. Maternal attitudes-To what extent do mothers hold attitudes about gender differences in worthiness and rights, perceive labor market discrimination against girls and women, or have expectations of future support from sons? We explore these attitudes as the backdrop of household educational decisions.

\subsection{Perceptions of the capabilities and worthiness of girls and boys}

First, we consider the question of whether families exhibit "traditional" gender attitudes related to abilities and rights. Fig. 2 lists mothers' responses to a series of statements about gender equality in basic abilities and opportunities for social advancement: "Parents Should Encourage Girls To Think As Independently As Boys;" "Given Equal Opportunities, Women Can Achieve The Same Things As Men;" "Girls Should Enjoy The Same Opportunities For Education As Boys;" "And "If They Work Hard, Girls Can Do As Well As Boys In School." Strikingly, Across These Questions, Very Few, mothers - fewer than 5\% - actively disagreed with an egalitarian position. The vast majority of mothers reported egalitarian views on these questions. These results do not suggest that overtly discriminatory views about the essential capabilities or worthiness of girls per se are a widespread barrier to girls' educational opportunities in rural Gansu.

\subsection{Perceptions of labor markets}

Perceptions about the labor market outcomes of schooling are commonly cited as potentially important influences on parental demand for schooling, and if the perceptions are that gender discrimination prevents girls from translating education to good jobs, this may hurt parents' willingness to support girls' education. Fig. 3 shows mother's attitudes about the economic outcomes of schooling. Mothers thought education was important, in an absolute sense. The vast majority believed that junior and senior high school education influence earnings, for both boys and girls. Yet, almost half of mothers - $45.6 \%$ - agreed that education influences sons' income more than daughters. These results suggest that household economic calculations could affect the incentives for educating girls, for a sizeable proportion of children.

\subsection{Expectations of future support}

In China, the expectation that sons will provide for parents in old age is often cited as an incentive for parents to favor the education of sons over daughters. Table 1 addresses this contention, showing responses to a variety of questions related to mothers' expectations of future support and links between these expectations and their possible association with educational decisions. First, a majority $-57.2 \%$ of the sample - agreed with an abstract statement of the view that parents should rely on sons for old-age support. When asked a more concrete question about own expectations for future support, only a few mothers in this sample, $15.4 \%$, did not expect at least some economic support from children in the future. Further, when asked which child would provide them with the most economic support, a sizeable majority of $81.2 \%$ of mothers expected it to come from sons.

Next, we want to understand whether differences in expectations of support were linked, in mothers' minds, to attitudes about educating girls. We find that a majority $-68.4 \%$ of mothers - disagreed with the notion that educating girls was useless because girls marry out of the family (Table 1). Yet, a significant minority $-17.9 \%$ of the mothers - agreed with the view that educating girls was a waste. 
These results suggest that expectations of future support are skewed enough toward sons that cost-benefit analyses might significantly influence calculations about extending educational opportunities to children. While only a minority of mothers agreed with the rather extreme view that educating girls was useless, the rate of agreement with this perspective was almost one in five mothers. Further, mothers need not agree with the view that educating girls is useless in order to act on the strong incentives to privilege son's education offered by old-age support expectations.

8.4.1. Parental investments-To what extent do differences in incentives to families for educating girls and boys translate to different investments for girls and boys? This section investigates the scope of gender differences in parental investments, and their linkages to attitudes about co-residence and the labor market.

Table 2 shows provision of resources by child's gender, along with statistical tests of differences by gender. Asterisks indicate significant gender differences by $t$-tests of mean differences in economic resources and number of books and by chi-square tests of independence for homework help, time competition, and aspirations. Table 2 shows no noteworthy gender differences for economic investments in children. Neither the gender difference in provision of books nor that in helping children with homework was significant. However, differences that are more striking emerge in the two categories of time competition and aspirations. Mothers report that they are significantly more likely to call on girls to do regular housework. ${ }^{7}$ About $17 \%$ of girls are never called upon to do housework, compared to about $31 \%$ of boys. Further, mothers had significantly different aspirations for girls' and boys' education, with higher aspirations for boys. About $25 \%$ of girls' mothers aspired to a college education for their girls, compared to about $29 \%$ of boys' mothers. Another $37 \%$ of girls' mothers and $46 \%$ of boys' mothers aspired to a senior high school education. Despite differences, maternal aspirations for boys and girls were very high, relative to what the future was likely to hold.

8.4.2. Educational performance-Table 3 shows descriptive statistics for various dimensions of school performance categorized by gender. Asterisks indicate significant gender differences by, t-tests of mean differences in math and language scores and by chi-square tests of independence for homework time, wanting to attend school, academic confidence, and aspirations. Table 3 shows that compared to boys, girls have lower aspirations, but they have similar or better achievement, similar levels of alienation, and more academic confidence.

Thus, it is only in child's educational aspirations where a significant difference emerges that is unfavorable to girls. Significant gender differences in language achievement and in academic confidence also emerge, but these gaps actually favor girls. These results suggest that any factors that are producing gender disparities in aspirations work through girls' realistic assessment of their future opportunities, more than through their efforts toward schooling, their assessment of their own innate abilities, or their performance.

8.4.3. Attitudes, investments, performance and educational attainment-Table 4 shows regression models of children's years of schooling in 2007. Model 0, the baseline model with only gender and age included, shows that, overall, boys enjoy just under one-third of 1year advantage in schooling. Model 1 adds the attitudinal variables in Box 1 in Fig. 1. These results show that children in households where mothers espouse or do not actively disagree

\footnotetext{
${ }^{7} \mathrm{We}$ do not have items in our questionnaires that directly address how often children are asked to perform a household chore or farmrelated chore, but we do have questions in the household questionnaires about time allocation to household and farm work. The household head reported the amount of time children participate in farm chores (chopping wood and carrying water) and household chores (cooking, washing, other housework, and caring for the sick and elderly). We conducted analyses with these variables and our findings are consistent with Table 2: girls spend more time on household chores than boys. This gap was not compensated by differences in time spent on farm chores: there was not a statistically significant difference in the time that boys and girls spend chopping wood or carrying water.
} 
with the traditional view that educating daughters is useless are significantly disadvantagedthey attain about one-fourth to about two-fifths years less education by 2007. Children of mothers who disagreed with the statement that education influences son's more than daughter's future income had marginally significantly higher attainment. However, accounting for attitudes does not erode the overall gender gap; it remains at about one-third of a year. Of course, a key test here is whether maternal attitudes might affect girls and boys differently, and so we tested gender interactions. However, none proved significant, a finding which indicates that girls and boys were both disadvantaged by living in households characterized by traditional attitudes.

Model 2 includes only the investment variables in Box 2, and here the early economic investments, helping child with homework, and early aspirations of mothers matter for educational attainment in 2007. Recall that maternal aspirations was one of the only variables that showed a significant, if moderate, advantage for boys. Book provision is marginally significant. Accounting for investment differences brings the gender gap in later attainment down to about 24 years. Model 3 adds only the performance variables in Box 3, and here it is striking to note that all except hours spent on homework are significantly associated with subsequent attainment. Hours spent on homework is marginally significant, with the middle category of 1-2 $\mathrm{h}$ showing a positive effect compared to less than $1 \mathrm{~h}$, and the high category of greater than $3 \mathrm{~h}$ showing a negative effect. Recall that girls were advantaged in some of these measures, relative to boys, and only significantly disadvantaged in aspirations. It is very clear, comparing the gender coefficient here to that in the baseline model, that performance does not explain gender gaps in attainment, which remains at about a third of a year.

Model 4 incorporates all coefficients from the earlier models. Significant variables in earlier specifications largely persisted here, with the exception that the effect of the variable "Education influences son's more than daughter's future income" drops to insignificance. Similarly, provision of books and help with homework drop to insignificance, though the patterns are the same as in earlier models. This change suggests that these factors are correlated with other variables conducive to children's attainment. Sometimes being asked to do chores becomes marginally significant in this specification, and is positive, suggesting an ambiguous educational consequence of the earlier finding that mothers of girls are more likely to call on them to do chores. The fact that this variable is insignificant in most specifications, and marginally positive in this one, suggests that chores are not seriously impeding the educational progress of girls.

Model 5 includes all variables significant or marginally significant in Model 4, and Model 6 adds to Model 5 controls for socio-economic and demographic background factors. The maternal discriminatory attitudes measure becomes just marginally significant with controls in Model 6. The smaller scope and reduced significance of the maternal discriminatory attitudes variables in Model 6 suggests the linkage of these attitudes to socio-economically disadvantaged households. The help with homework variable becomes insignificant in Model 6 , which is probably due to the fact that households with better-educated parents are more likely to be able to help with homework. For other variables, the sign and significance in earlier models persists across these specifications. The control variables included in Model 6 operate as expected-parental education and wealth are positively associated with subsequent attainment. A more surprising finding is that, net of other factors, having older sisters and younger brothers are both associated with higher attainment in 2007. The older sister finding is not as surprising, given common speculation that older girls may support younger brothers to stay in school. The younger brothers effect is a puzzle. It is possible that this result reflects that households able to implement a preference for sons have more resources in ways not captured in our socio-demographic controls. Finally, our analysis tested for any significant gender interactions with each variable in Model 5, and found none. 
8.4.4. Summary-Results show that at ages 9-12, rural girls in Gansu compare well to boys in terms of parental economic investments and provision of a learning environment, own achievement, industriousness, academic confidence, and alienation from school. A significant gap favoring boys emerges in mothers' calling on children for chores and in mothers' and children's own aspirations. In explaining the gender gaps that do emerge, evidence suggests that few mothers think that girls are less capable or worthy of investment than boys, but substantial proportions of mothers expect future support from sons, and some mothers link this expectation to the view that investing in girls is a waste. However, none of these hypothesized mechanisms of gender inequality fully explain away the modest gender gap that emerges in attainment 7 years later, in part because some early experiences favor boys, while others actually favor girls.

\section{Analysis of case studies}

We have argued here that, despite persisting parental attitudes that favor boys in some respects, parents aspirations tend to be high for girls as well as boys. Some may doubt the willingness of parents to report discriminatory attitudes in the context of a survey interview. Thus, we have tried to complement our attitudinal results by focusing also on more objective measures: we have presented evidence to suggest that investments in girls and boys early on in school are not very different, and that girls' performance is similar to and even exceeds boys' in some dimensions. Here, we offer evidence drawn from fieldwork about the key parental attitude findings about aspirations for girls and boys. We present two illustrative case studies of rural parents with both a son and a daughter that offer examples of commonly expressed views about education among families making decisions for sons and daughters.

\section{Case 1: The Zhu family}

Zhu Hanqi was 13 years old and in sixth grade at the time of fieldwork. He was considered a high-performing student. His older sister, Zhu Yuqin, was 15 years old and in seventh grade. Zhu Hanqi lived with his parents and grandmother. Zhu Hanqi's parents owned a restaurant on the main road that cuts through Shaoxingwen Township. The Zhu family had owned the restaurant for 11 years at the time of the study. Mr. and Mrs. Zhu had grown up in the village where they currently resided, and both had attended the local primary school. Mr. Zhu had completed fifth grade, and Mrs. Zhu had completed third grade. In addition to owning the restaurant, the family of five owned five $m u^{8}$ of land. Mr. and Mrs. Zhu were in their late 30s.

During the first home visit with the Zhu family, Mr. and Mrs. Zhu, grandmother Zhu, and Zhu Yuqin were present. Mr. and Mrs. Zhu smiled widely as they explained that Zhu Yuqin was home from school because the older students were taking examinations. They were eager to have Zhu Yuqin practice her English and learn how to improve her study habits from a foreigner. The home visit took place both in their restaurant and in their home located behind their restaurant. Their one-room cement home was filled with two faux leather wingback chairs, a slender table wedged in between the two chairs, a bed opposite the chairs, a desk with a chair, and a coal stove in the center of the room. The ceiling was decorated with newspapers, similar to most rural homes in the area.

Mr. and Mrs. Zhu leaned a little closer and the pace of their speech quickened as they explained their educational aspirations for their children. They said emphatically, "Of course we have aspirations! We do not expect our children to do any chores, because we hope that they will do well on their examinations." When asked if their aspirations were similar for both their son and daughter, Mr. Zhu emphasized strongly that they were. He said, "For both of our children,

\footnotetext{
${ }^{8} \mathrm{~A} т и$ is a measurement and is equal to $1 / 15$ th of a hectare. There are about $3885 \mathrm{mu}$ in a square mile. The average land amount per household in the GSCF was $9.54 \mathrm{mu}$.
} 
we want them to succeed in school and not suffer." Mrs. Zhu quickly added, "There is only one way out [of rural areas] for rural children. They must test into a good school."

When the discussion turned specifically to their children's academic studies, differences between the study habits and perceived academic ability of their son and daughter emerged. The tone in Mrs. Zhu's voice became calm and matter-of-fact when she pointed out a distinction between her daughter and son. She said, "Our daughter is more studious and has better study habits than our son." She went on to say that her son was smarter, but that he liked to play too much. Mr. and Mrs. Zhu viewed being studious as a positive trait, and stated explicitly that their daughter set an example for their son. Mr. and Mrs. Zhu, Zhu Yiqin and Zhu Hanqi all indicated that whenever Zhu Hanqi had questions related to schoolwork, he turned to Zhu Yiqin for help.

\section{Case 2: The Gao family}

Gao Ling was 13 years old and in sixth grade, and was a high-performing student. Her younger brother, Gao Xiongwen, was 12 and in third grade. Gao Ling and her family lived in the $\mathrm{Lu}$ village, about $2 \mathrm{~km}$ from school. Mr. and Mrs. Gao were both in their late 30s. Mr. Gao had graduated from middle school and his wife had completed primary school. The family of four had nine $m u$ of land. Mr. and Mrs. Gao both worked temporary jobs as day laborers. At the time of the interview, Mrs. Gao was working on road construction.

The Gao family lived in a small family compound made of mud and thatch. Their small courtyard included a small mud pen for a sheep and a pig. The courtyard did not have room for planting fruits or vegetables. The home consisted of one main room, which served as the living room, kitchen, and sleeping quarters. There was a bed, sofa, table and chair, coal stove, and a television.

During the second home visit, while Mr. Gao was recounting his educational experiences, his educational aspirations for his children emerged. Referring to his own childhood, he spoke as follows:

Back then, things were different. You did not need to complete junior secondary school. There were many who did not continue past primary school. Back then, families had many children; [parents] allowed those who performed well to continue on in school and it did not matter if those who performed poorly dropped out. It is not like today. We have two and we are prepared to support them both. Reaching 99\% completion is not acceptable.

To Mr. Gao, the smaller number of children fueled his interest in supporting his children's education, and not their gender. Mr. Gao tensed and his face became very serious when he explained, "I want them to get into a good school, [I do not want] them to be like their mother and me. I don't want them to suffer." When asked about his specific educational aspirations for his children, Mr. Gao raised his head towards the ceiling, as if indicating the higher, the better. He described his educational aspirations his children as follows:

I have high aspirations, but we'll have to see if they can be realized, I hope that [my daughter] will make it to college...We'll see when she gets to middle school, you can't tell in primary school, [her] learning is dependent on herself...I feel the same about my son's learning. They both need to study well.

Consistent with the high maternal expectations found in the survey data, Mr. Gao held high educational aspirations for his children: he hoped that they would make it to tertiary education. Mr. Gao believed that as parents, he and his wife worked hard to provide the funding needed to keep Gao Ling and Gao Xiongwen at school, and could do nothing more. He told his children that their job was to focus on studying, a task that his daughter seemed to be taking to heart 
better than his son. Mr. Gao described his daughter Gao Ling as "serious and studious...". He went on to say, "My son is intellectually smarter, but that is not enough. My daughter is studious." Mrs. Gao agreed, stating, "Our son is smarter, but his achievement is average." Mr. Gao added, "he just doesn't focus on his studies, he likes to play too much." Gao Ling was considered one of the top sixth grade students at the start of the school year. She was ranked third among all sixth graders in the school (out of 75 students). Gao Xiongwen, on the other hand, had repeated a grade in the past and his academic performance was, as his mother said, average.

\section{Summary}

In these two case studies, and in the fieldwork, more broadly, rural parents appeared to express similar, high aspirations for boys and girls. Parents did not want their children - boys or girls - to experience a lifetime of hardship, and they viewed education as the main avenue of escape from this fate. Both sets of parents interviewed for these case studies, as well as other parents interviewed during fieldwork, worked hard and sacrificed in hopes of increasing the odds that their children - boys and girls - could attain those high aspirations. It is striking that in both cases, girls' school performance was better than boys', but parents perceived boys as being smarter. Despite this apparent bias, these parents appreciated the value of the work ethic that they saw in their girls, and thought that it would serve them well at school and into the future. These views about male and female students were commonly voiced by parents in the larger field study.

\section{Discussion and conclusions}

This paper began by laying out a framework based on theory and empirical research about gender gaps in education in rural, developing societies, commonly employed to explain the gender gap in education in rural China. In fact, analyses show that many aspects of this framework breakdown. By mothers' reports in the survey, and based on interviews conducted as part of the field study, relatively few rural families think daughters are less capable or less worthy of investment, contradicting Hypothesis $1 .^{9}$

In addition, by many important measures of parental investments, there is no disadvantage for girls, nor is there a gap favoring boys in many measures of children's own school performance, contradicting Hypotheses 4 and 5. Further, the one gap in children's performance that favored boys, in aspirations, while important, should not mask the fact that aspirations among boys and girls are extraordinarily high. ${ }^{10}$ A full $46 \%$ of girls and $51 \%$ of boys aspire to a college education, in a setting where the average education of mothers is less than 5 years, and the average education of fathers is less than 7 years. Findings of egalitarianism in many aspects of educational investments and performance in one of China's poorest rural settings are strikingly similar to results from Tsui and Rich's (2002) findings in a much more developed urban setting. Most significantly, by 2007, attainment differences were not very striking: About One-Third Of A Year In Attainment.

\footnotetext{
${ }^{9}$ There are some important caveats to these findings. The obvious criticism of the finding that most mothers express egalitarian ideas about the abilities and rights of girls is that this view is highly suspect to social desirability bias. Our measure of discriminatory attitudes is probably conservative, missing those mothers who hold inegalitarian views but are unwilling to voice them in public. Interestingly, though, ideas regarding co-residence with sons are similarly very traditional, and have been the target of government public awareness campaigns, yet mothers were quite willing to express traditional attitudes for these measures. A second criticism is that we have focused on mothers' attitudes, rather than fathers,' a choice necessitated by practical reasons during data collection. We acknowledge this concern. However, field visits and in-depth interviews conducted as part of this project have yielded results consistent with those reported here regarding a lack of overtly discriminatory views on the part of mothers and fathers. One advantage to focusing on mothers is that, in most cases, mothers are more likely to be directly involved with children's day-to-day socialization.

${ }^{10}$ For a succinct discussion of the interpretation of educational aspirations and the phenomenon of high aspirations among disadvantaged youth in the US context, see Kao and Thompson (2003).
} 
Complicating the picture, however, findings also emerge that are consistent with traditional attitudes about family responsibilities and gender roles. Girls are more frequently called on for chores, and these findings are very consistent with research in other rural Asian settings suggesting that family considerations about future support are a key element in genderdifferentiated socialization of children, and that girls are more likely to be called on for family work at a younger age (Mahmud and Amin, 2006; Rothchild, 2006). Yet, our results do not suggest that chores are associated with lower attainment. In addition, consistent with Hypotheses 2 and 3, it remains true that rural families expect future support from sons more than from daughters, and many rural families perceive that returns to education will be better for their sons' future than daughters' future. Other work in Gansu has suggested that a scale of mothers' traditional gender attitudes, which includes attitudes about future co-residence and other attitudes, can be linked to educational aspirations for their daughters (Zhang et al., 2007). The same study also showed that gender bias in mothers' aspirations was more pronounced among mothers who hold traditional gender values, and that mother's aspirations predicted subsequent persistence in school. Yet, evidence indicates that the continuation of traditional gender roles is not translating to stark gender gaps in attained schooling in 2007.

It is interesting to note that there is strong evidence of sharply rising preference for sons in births and in health in early life in China, and in Gansu. Sex ratios at birth, males born per hundred females born, are about 106 in populations where no human intervention is occurring. In Gansu, estimates showed normal sex ratios at birth in 1981 (106.27); elevated sex ratios in 1989 (110.82); and extremely elevated sex ratios by 1999 (119.35) (Lai, 2005). ${ }^{11}$ Moreover, the mortality risk faced by infants also shows a deteriorating position for girls Moreover, the mortality risk faced by infants also showsa deterioratingposition for girls-a departure from the biologically expected situation of elevated risk for males. Lai (2005) estimates that the ratio of male infant mortality rates to female infant mortality rates dropped sharply from 112.18 in 1981 to 94.09 in 1989 to 72.52 in 1999 (Lai, 2005). Boys' infantmortality rates were relatively stationary during this period at 35-36 per thousand, but girls' rose substantially from 30.78 in 1981 to 36.73 in 1989 , to 50.19 in 1999 (Lai, 2005).

Thus, there is a stark disconnect between trends in sex ratios at birth and infant mortality, on the one hand, and the investments in education that occur among older children, once they have become active family members. Evidence from rural Gansu suggests that rural families' attitudes toward their daughters' education in one of China's poorest rural settings are generally more egalitarian and more complex than commonly portrayed. The portrait of relatively similar investments in education and educational outcomes is striking in light of the overwhelming expectation of rural households that sons are needed for old-age support, and the evidence that parents are increasingly acting in line with this need as they choose whether to bear children and nurture them as infants.

\section{Acknowledgments}

The Gansu Survey of Children and Families is supported by a grant from the United Kingdom Economic and Social Research Council and Department for International Development (ESRC RES-167-25-0250). Earlier support for data collection came from The Spencer Foundation Small and Major Grants Programs, The World Bank, and NIH Grants 1R01TW005930-01 and 5R01TW005930-02. Qualitative data collection by the second author was funded by grants from Harvard University (a Frederick Sheldon Travel Grant and a Center for International Development Travel Grant) and a David L. Boren Graduate Fellowship.

\footnotetext{
${ }^{11}$ High sex ratios at birth are probably attributable to a combination of under-reporting of girl births and prenatal sex selection, with either strategy enabling families to continue to try for a boy. In our data, there is clear evidence that parents continue to bear children if earlier children are daughters, in order to have at least one son. Girls tend to have more siblings overall and are more likely than boys to have brothers, especially younger brothers.
} 


\section{References}

Andors, P. The Unfinished Liberation of Chinese Women 1949-1980. Indiana University Press; Bloomington: 1990.

Bauer J, Wang F, Riley NE, Xiaohua Z. Gender inequality in urban China: education and employment. Modern China 1992;18(3):333-370.

Connelly R, Zheng Z. Determinants of school enrollment and completion of 10 to 18 year olds in China. Economics of Education Review 2003;22(4):379-388.

Connelly, R.; Zheng, Z. Enrollment and graduation patterns as China's reforms deepen 1990-2000. In: Hannum, E.; Park, A., editors. Education and Reform in China. Routledge; London: 2007.

Emerson, RM.; Fretz, RI.; Shaw, LL. Writing Ethnographic Fieldnotes. Chicago University Press; Chicago: 1995.

Gansu Socio-economic Development Report. 2001. http://www.gs.stats.gov.cn/tjzh/gb/200209020100.htm (accessed on 10/12/2002)

Gansu Statistics Bureau. ND. Sampling documentation for the Gansu Survey of Children and Families, English translation. Mimeo; Lanzhou, China:

Greenhalgh S. Controlling births and bodies in village China. American Ethnologist 1994;21(1):3-30.

Hannum E. Market transition, educational disparities, and family strategies in rural China: new evidence on gender stratification and development. Demo-graphy 2005;42(2):275-299.

Hennon CB, Photiadis J. The rural appalachian low-income male: changing role in a changing family. Family Coordinator 1979;28:608-615.

Honig, E.; Hershatter, G. Personal Voices: Chinese Women in the 1980's. Stanford University Press; Stanford, California: 1988.

Hooper, B. Gender and education. In: Epstein, I., editor. Chinese Education Problems, Policies, and Prospects. Garland, New York: 1991.

Jacka, T. Women's Work in Rural China: Change and Continuity in an Era of Reform. Cambridge University Press; Cambridge: 1997.

Jin X, Li S, Zhu C. An elementary analysis on intergenerational property transfer mode in various marriage forms in rural China. Population and Economics 2002;130:18-24. in Chinese.

Kao G, Thompson JS. Racial and ethnic stratification in educational achievement and attainment. Annual Review of Sociology 2003;29:417-442.

Lai D. Sex ratio at birth and infant mortality rate in China: an empirical study. Social Indicators Research 2005;70(3):313.

Li J, Lavely W. Village context, women's status, and son preference among rural Chinese women. Rural Sociology 2003;68:87-106.

Lin, J. Education in Post-Mao China. Praeger, Westport: 1993.

Lo, BLC. Primary education in China: a two-track system for dual tasks. In: Ruth, Hayhoe, editor. Contemporary Chinese Education. Croom Helm; Sydney: 1984.

Mahmud S, Amin S. Girls' schooling and marriage in rural Bangladesh Children's Lives and Schooling Across Societies. Research in Sociology of Education 2006;15:71-99.

Michelson, E.; Parish, W. Gender differentials in economic success: rural China in 1991. In: Entwisle, B.; Henderson, G., editors. Re-Drawing Boundaries: Work, Households, and Gender in China. University of California Press; Berkeley: 2000.

Miles, MB.; Huberman, AM. An Expanded Sourcebook: Qualitative Data Analysis. Sage Publications; Thousand Oaks: 1994.

Papanek H. Class and gender in education-employment linkages. Comparative Education Review 1985;29:317-346.

Ridgeway CL, Correll SJ. Limiting gender inequality through interaction: the end(s) of gender. Contemporary Sociology 2000;29:110-120.

Ridgeway CL, Correll SJ. Unpacking the gender system: a theoretical perspective on gender beliefs and social relations. Gender and Society 2004;18:510-531.

Rosen, S. New directions in secondary education. In: Hayhoe, R., editor. Contemporary Chinese Education. Croom Helm; Sydney: 1984. 
Rothchild J. Gendered homes and classrooms-schooling in rural Nepal children's lives and schooling across societies. Research in Sociology of Education 2006;15:101-131.

Sewell WH. A theory of structure: duality, agency, and transformation. American Journal of Sociology 1992;98:1-29.

Strauss, A.; Corbin, J. Basics of Qualitative Research: Techniques and Procedures for Developing Grounded Theory. Sage Publications; Thousand Oaks: 1998.

Summerfield G. Economic reform and the employment of Chinese women. Journal of Economic Issues 1994;28:715-732.

Tsui M, Rich L. The only child and educational opportunity for girls in urban China. Gender and Society 2002;16(1):74-92.

UNESCAP. Population and Family Planning in China by Province: Gansu Province. 2003. [cited July 22 2003]); available from http://www.unescap.org/esid/psis/population/database/chinadata/gansu.htm

UNESCO Institute for Statistics. Gross Enrollment Ratios. 2005. [cited October 15, 2005>], available from http://stats.uis.unesco.org/ReportFolders/reportfolders. aspx

Wang S. Educational level of female teenagers and young adults declines. Chinese Education: A Journal of Translations 1989;22(2):21.

Wilson SM, Peterson GW, Wilson P. The process of educational and occupational attainment of adolescent females from low-income, rural families. Journal of Marriage and the Family 1993;55:158-175.

Wolf, M. Stanford University Press; Stanford: 1985. Revolution Postponed: Women in Contemporary China.

World Bank. China: Overcoming Rural Poverty. World Bank; Washington D.C.: 2000.

Zhang Y, Kao G, Hannum E. Do mothers in rural china practice gender equality in educational aspirations for their children? Comparative Education Review 2007;51(2):131-157.

Zhou X, Moen P, Tuma NB. Educational stratification in urban China: 1949-1994. Sociology of Education 1998;71:199-222. 


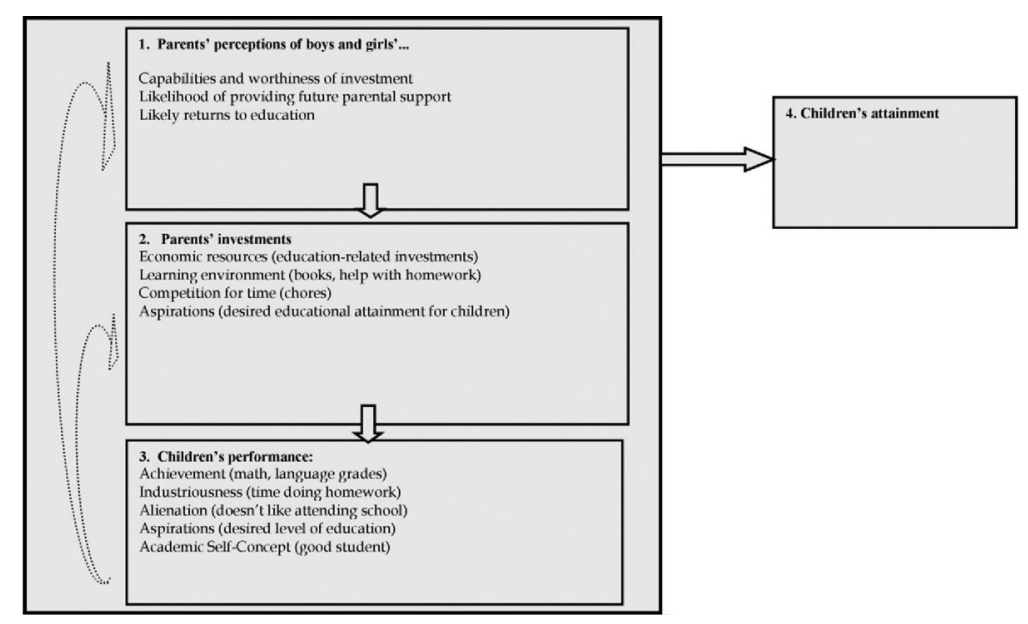

Fig. 1.

Framework. 


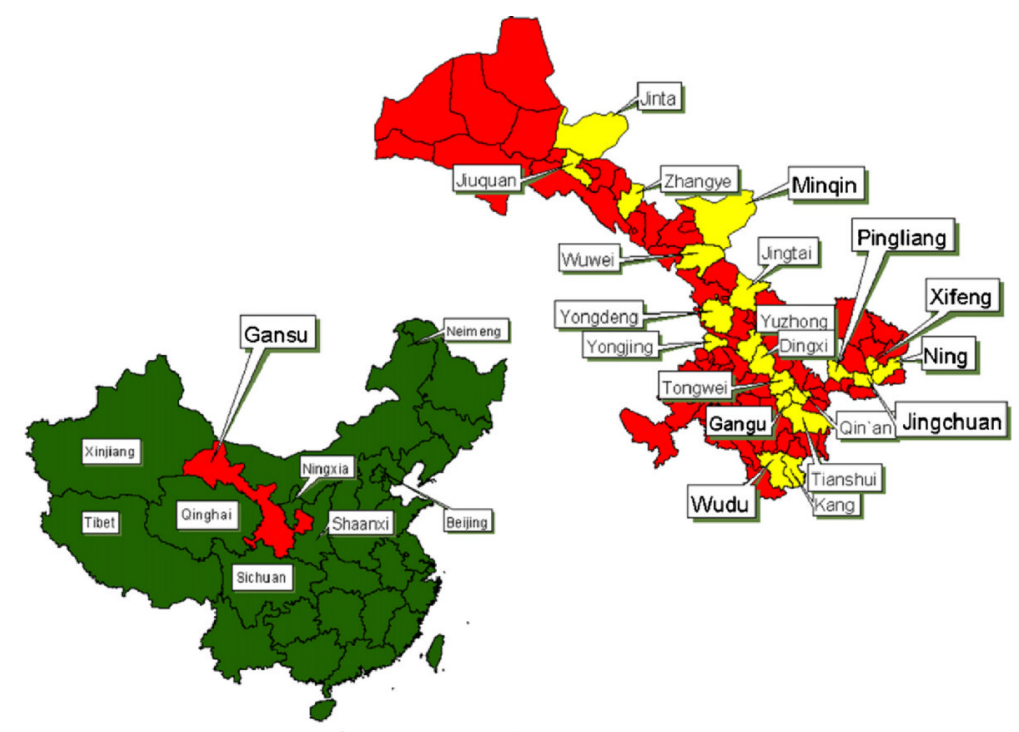

Map 1.

Gansu Province, survey counties marked. 


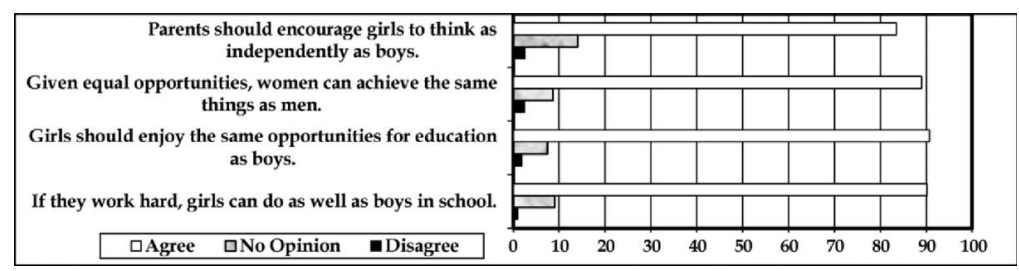

Fig. 2.

Mother's attitudes about abilities and opportunities. 


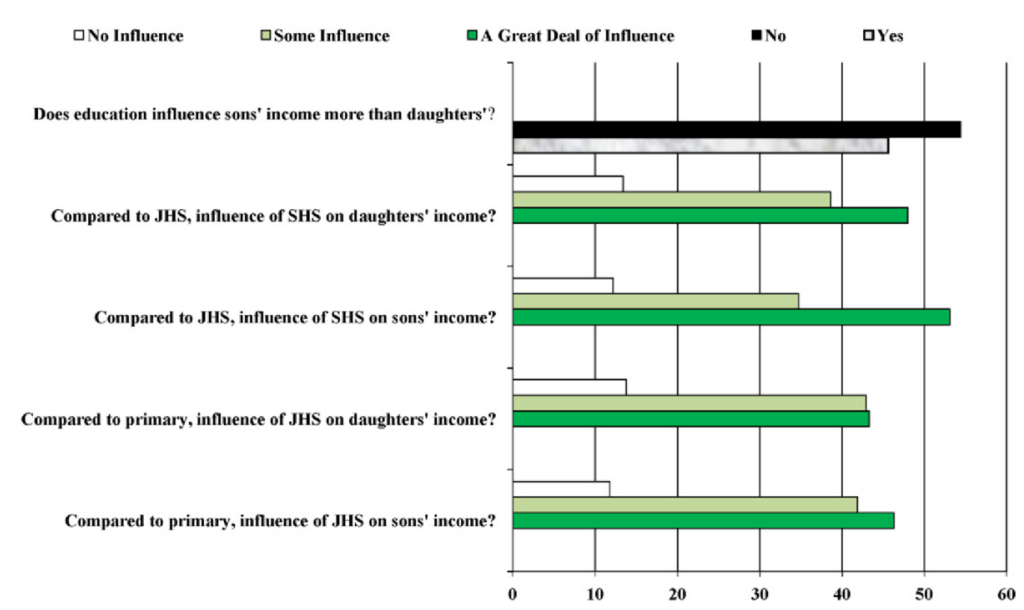

Fig. 3.

Mother's perceptions of returns to schooling. 
Table 1

Mother's attitudes and expectations about co-residence and future support (in \%).

\begin{tabular}{llcc}
\hline Attitudes and expectations & Disagree & No opinion & Agree \\
\hline Parents should rely on sons for old-age support $(N=1989)$ & 22.9 & 19.9 & 57.2 \\
Schooling is useless for girls since they marry and leave home $(N=1997)$ & 68.4 & 13.7 & 17.9 \\
\hline & Very little/none & Some & A lot \\
\hline $\begin{array}{l}\text { How much financial help do you think you will get from your children? }(N= \\
1953)\end{array}$ & 15.4 & 66.3 & 18.3 \\
\hline & & Son & Daughter \\
\hline Which child will give the most financial help in the future? $(N=1907)$ & 81.2 & 18.8 \\
\hline
\end{tabular}




\section{Table 2}

Resource provision by child's gender.

\begin{tabular}{|c|c|c|c|}
\hline Resource provision & & Girls & Boys \\
\hline \multicolumn{4}{|l|}{ Economic resources } \\
\hline Educational expenditures last semester $(N=2000)$ & (Mean) & 156.1 & 160.7 \\
\hline \multicolumn{4}{|l|}{ Learning environment } \\
\hline \multirow[t]{2}{*}{ Number of books owned by child $(N=1775)$} & (Mean) & 14.8 & 15.7 \\
\hline & Never & 15.6 & 14.0 \\
\hline \multirow[t]{2}{*}{ Helping child with homework $(N=1985)$} & Occasionally & 50.1 & 49.4 \\
\hline & Often & 34.3 & 36.6 \\
\hline$\chi^{2}$ & & $1.63(2)$ & \\
\hline \multicolumn{4}{|l|}{ Competition for time } \\
\hline & Never & 17.3 & 30.6 \\
\hline \multirow[t]{2}{*}{ Frequency child does regular chores $(N=1998)$} & Occasionally & 64.1 & 57.6 \\
\hline & Often & 18.7 & 11.8 \\
\hline$\chi^{2}$ & & $55.47(2)^{* * *}$ & \\
\hline \multicolumn{4}{|l|}{ Aspirations } \\
\hline & Primary & 5.9 & 3.2 \\
\hline & Junior & 31.2 & 21.8 \\
\hline \multirow[t]{3}{*}{ Highest level of education child can achieve $(\mathrm{N}=1956)$} & Senior & 37.0 & 45.7 \\
\hline & College & 24.9 & 28.6 \\
\hline & Other & 1.0 & 0.8 \\
\hline$\chi^{2}$ & & $36.13(4)^{* * *}$ & \\
\hline $\begin{array}{l}\text { Note: Asterisks denote significant results by chi-squared or } \\
* \quad p<0.1 \text {. }\end{array}$ & & & \\
\hline \multicolumn{4}{|l|}{$\begin{array}{r}* * \\
\quad p<0.05 .\end{array}$} \\
\hline $\begin{array}{l}* * * \\
\quad p<0.01 .\end{array}$ & & & \\
\hline
\end{tabular}




\section{Table 3}

Educational performance by child's gender.

\begin{tabular}{|c|c|c|c|}
\hline Variable & & Girls & Boys \\
\hline \multicolumn{4}{|l|}{ School achievement } \\
\hline \multicolumn{2}{|l|}{ Math score $(N=1957)$} & 74.3 & 73.7 \\
\hline \multicolumn{2}{|l|}{ Language score $(N=1951)$} & 73.9 & $71.3^{* * *}$ \\
\hline \multicolumn{4}{|l|}{ Industriousness } \\
\hline \multirow{3}{*}{ Every day, how much time is spent doing homework? $(N=1984)$} & Less than $1 \mathrm{~h}$ & 43.6 & 45.6 \\
\hline & $1-2 \mathrm{~h}$ & 39.0 & 39.6 \\
\hline & $3 \mathrm{~h}$ or more & 17.4 & 14.8 \\
\hline \multicolumn{2}{|l|}{$\chi^{2}$} & $2.50(2)$ & \\
\hline \multicolumn{4}{|l|}{ Alienation } \\
\hline \multirow{4}{*}{ Usually I do not want to go to school $(N=1986)$} & Totally disagree & 48.1 & 47.6 \\
\hline & Somewhat disagree & 29.9 & 31.0 \\
\hline & Somewhat agree & 10.8 & 11.0 \\
\hline & Totally agree & 11.3 & 10.4 \\
\hline \multicolumn{2}{|l|}{$\chi^{2}$} & $.605(3)$ & \\
\hline \multicolumn{4}{|l|}{ Academic confidence } \\
\hline \multirow{3}{*}{ Are you a good student? $(N=1985)$} & No & 10.5 & 14.1 \\
\hline & Somewhat & 44.0 & 46.6 \\
\hline & Yes & 45.4 & 39.4 \\
\hline \multicolumn{2}{|l|}{$\chi^{2}$} & $9.90(2)^{* * *}$ & \\
\hline \multicolumn{4}{|l|}{ Aspirations } \\
\hline \multirow{6}{*}{ Highest level of education you want to achieve $(N=1983)$} & Primary & 5.8 & 3.8 \\
\hline & Junior & 10.3 & 9.2 \\
\hline & Senior & 19.4 & 15.1 \\
\hline & Junior trade & 9.4 & 9.7 \\
\hline & Senior trade & 9.2 & 11.3 \\
\hline & College & 45.8 & 50.8 \\
\hline \multicolumn{2}{|l|}{$\chi^{2}$} & $14.77(5)^{* *}$ & \\
\hline
\end{tabular}

Note: Asterisks denote significant results by chi-squared or t-test:

$*$

$p<0.1$.

**

$p<0.05$.

*** $p<0.01$. 


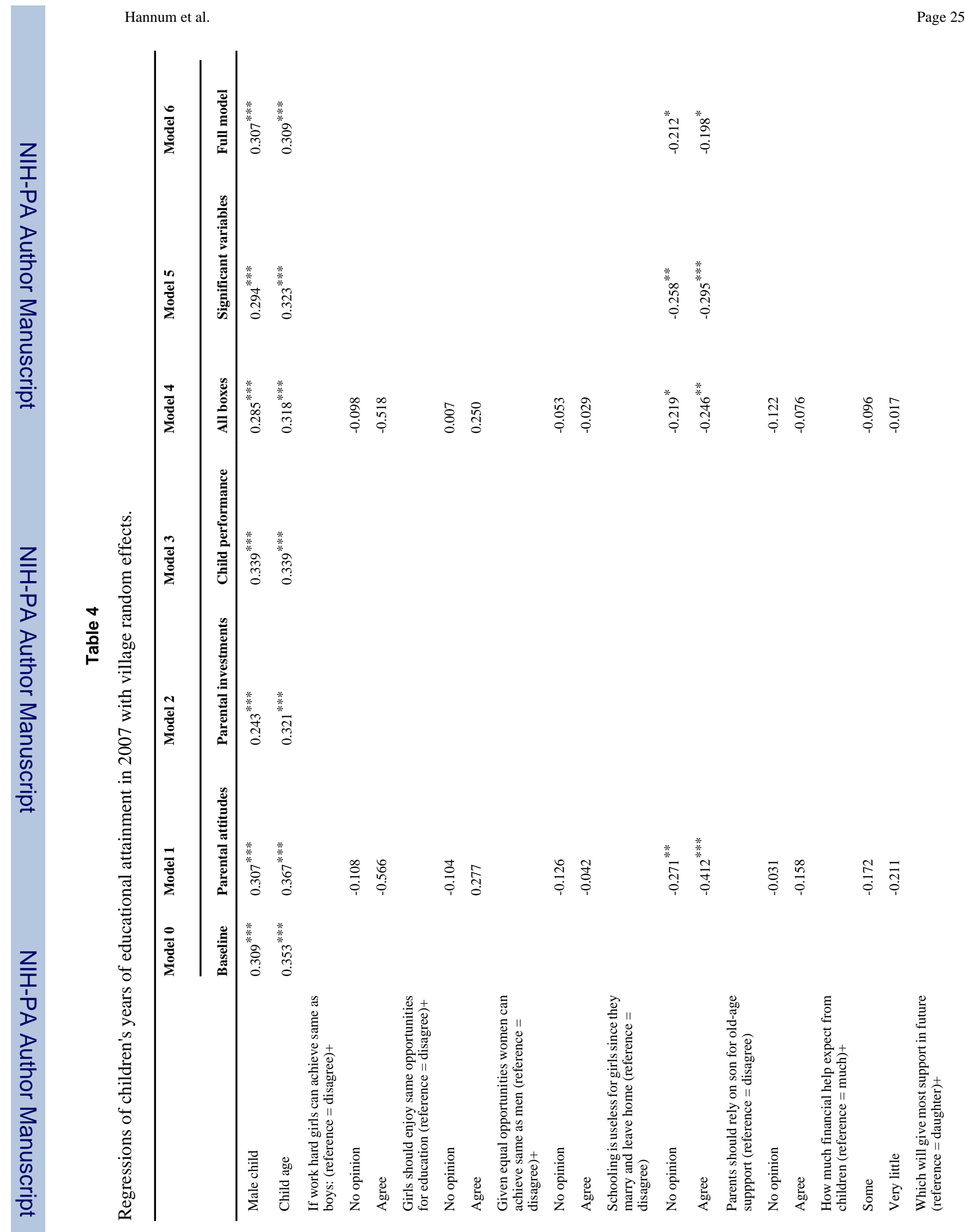

Int J Educ Dev. Author manuscript; available in PMC 2010 September 1. 
Hannum et al.

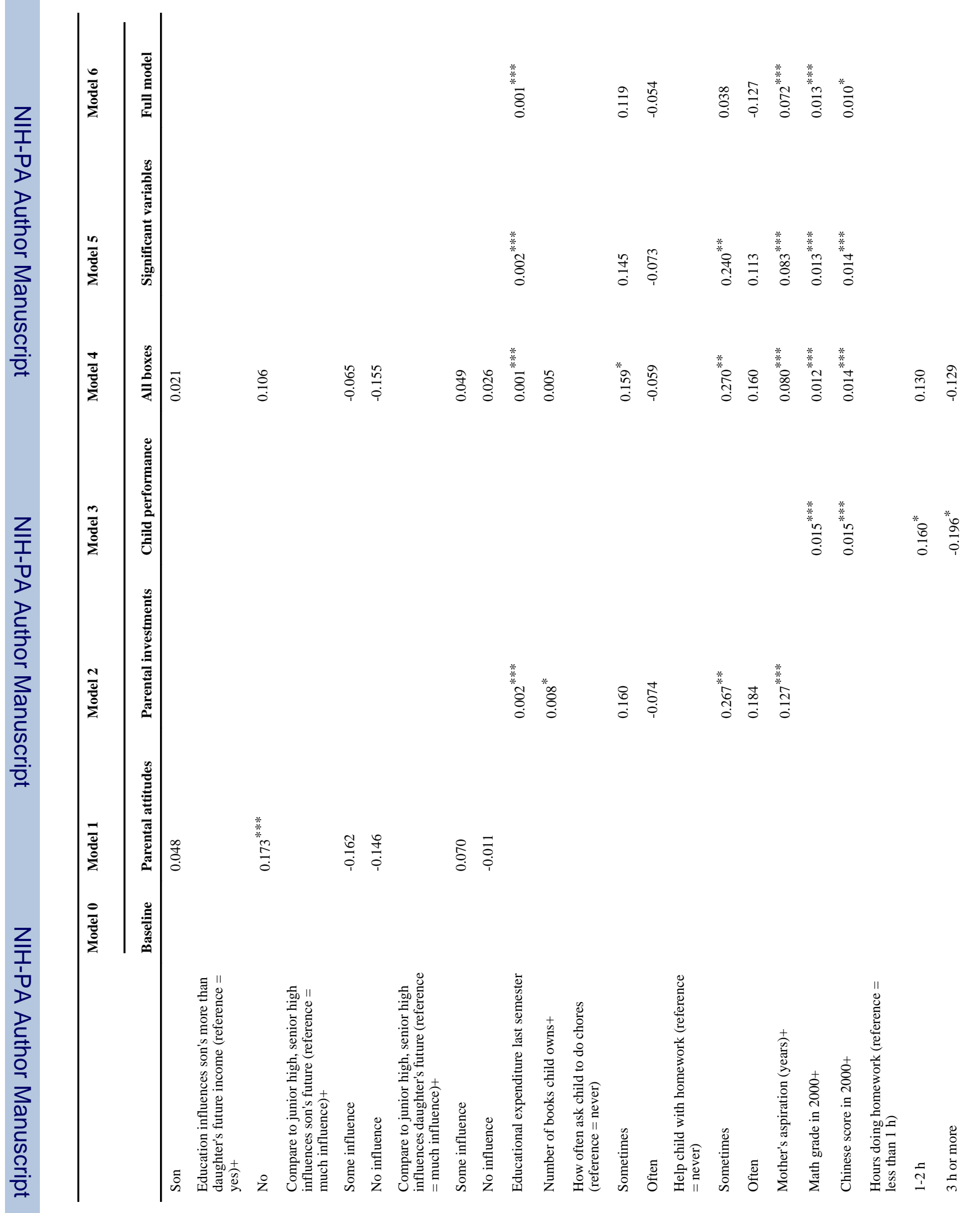

Int J Educ Dev. Author manuscript; available in PMC 2010 September 1. 


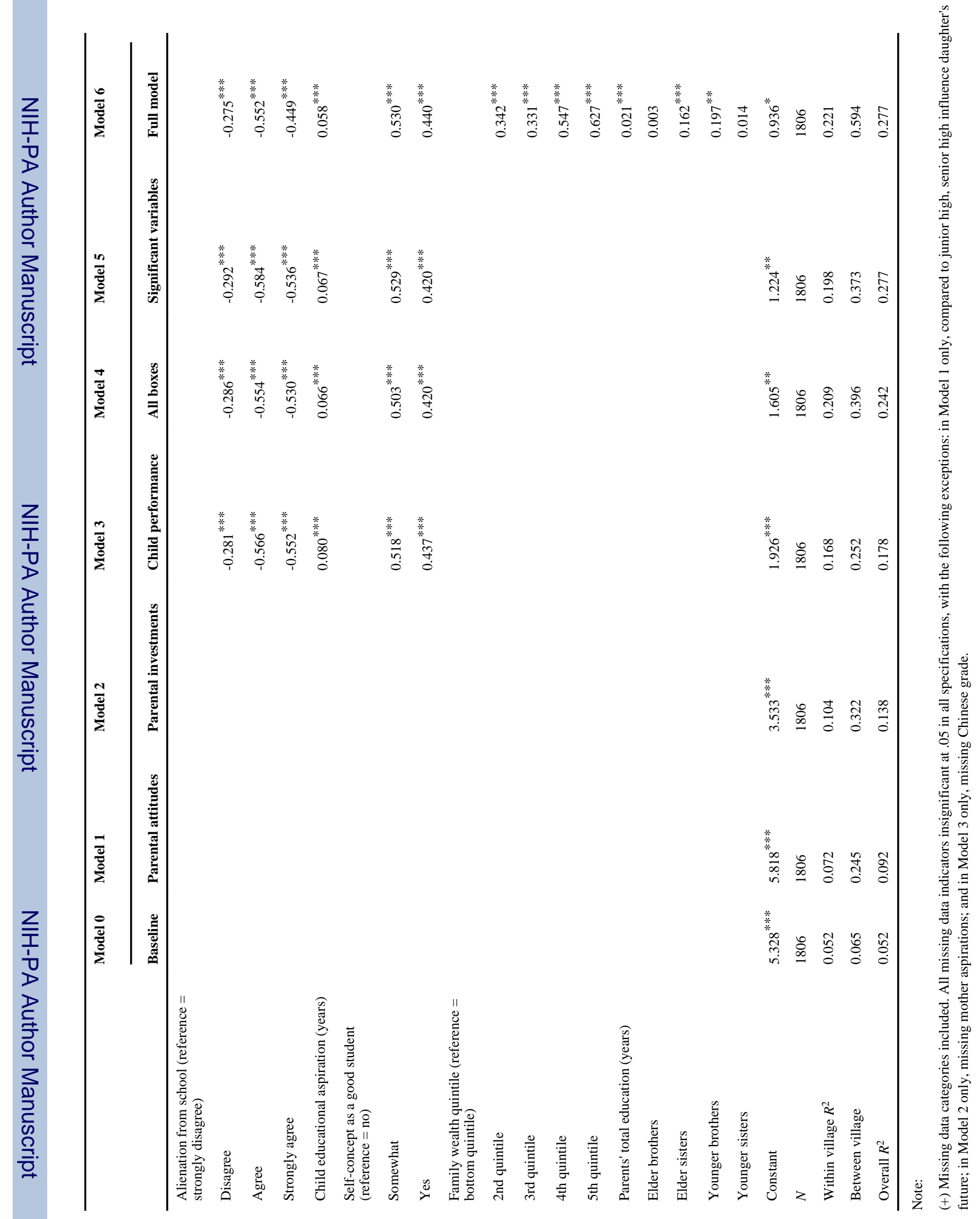
Int J Educ Dev. Author manuscript; available in PMC 2010 September 1. 
